\title{
Discussão dos Estudos Bioquímicos de Hipovitaminose "A"*
}

\author{
Maria do Socorro Silva Lima **
}

Sendo a avaliação bioquímica da vitamina $A$, o objeto de estudo que aqui se apresenta, trago algumas considerações que espero contribuam aos questionamentos, a partir de uma leitura onde tentei resgatar o que apreendi como mais relevante, em função do tempo em que se apresenta minha intervenção nesta mesa.

É inconteste a efetividade dos estudos bioquímicos como método mais seguro para avaliação nutricional.

No caso de investigação das carências específicas revestem-se esses estudos de peculiar eficácia sobre os demais, não apenas pelo fato de surpreender as deficiências nutricionais antes de suas manifestações clínicas, mas de diferenciá-las na medida em que alguns sinais e sintomas são comuns a várias determinaçōes.

As dificuldades operacionais e o custo em geral desses estudos é que são fatores limitantes para a maior freqüência de sua utilização, seja a nível de avaliação de programas, de diagnóstico ou para vigilància nutricional.

Trago a esta discussão, uma avaliação dos estudos mais recentes $(80.86)$ realizados neste país, constantes do último relato do Inan sobre o assunto em apreço.

$\mathrm{Na}$ tentativa de efetuar essa avaliação, utilizei ainda como referências para minha leitura a tese da professora Florisbela, o relatório sobre a reunião da Indonésia em 1980 e outros títulos igualmente importantes para compre. ensão do assunto.

Com relação aos estudos nacionais, tenho as seguintes observações, sobre os dados bioquímicos e suas discussões:

1 - No que se refere a determinação do retinol sérico, o citado documento do Inan, não explicita o método que foi utilizado para todos os estudos, impossibilitando, portanto, uma comparação mais precisa; sei entretanto por informações pessoais que, na tentativa de padronização, foi utilizado, a partir dos laboratórios, referência a nível de Norte e Nordeste, o método Berssey Lowry.

Neste sentido este foi um marco de avanço nos estudos da hipovitaminose A neste pais, pois os raros trabalhos 
antes de 1980, tiveram diversos métodos para o diagnóstico dessa carência.

2 - Com relação aos achados nos 10 estudos do período 80-86, verifica-se ser a hipovitaminose A um dos graves problemas de saúde pública a contribuir para 0 dramático perfil epidemiológico brasileiro.

Devo esclarecer que refiro-me a 3 estudos realizados em São Paulo, 1 em Minas Gerais, 2 em Recife, 1 na Paraiba, 2 no Rio Grande do Norte e 1 no Pará. Observo ainda que os do Rio Grande do Norte não constam no relato do Inan. $\mathrm{O}$ primeiro deles financiado pelo $\mathrm{CNPq}$, realizado em Natal em 1982, sob a nossa coordenação e a consultoria dos Drs. Flores e Malaquias (o qual teve sua abrangência reduzida por questões de recurso de 600 crianças para 200), tabelas 1 e 2 . $O$ ponto de corte foi $30 \mathrm{mg} / \mathrm{dl}$ e a prevalência foi de $17 \%$.

$\mathrm{O}$ segundo encontra-se em fase de tabulação e ainda não foi publicado, portanto não se inclui em nossos questionamentos.

3 - Avaliação e a proximidade ao zero do ponto de corte (30 mg a 20) para se estabelecer a deficiência e o indice de prevalência crítico. Citando de (Florisbela 1983, pag. 11) os niveis plasmáticos de retinol não refletem níveis intermediários de reserva hepática, pois os valores circulantes abaixo de $10 \mathrm{mg} / \mathrm{dl}$ só aparecem quando as reservas se esgotam, coincidindo com os sinais de xeroftalmia e queratomalacia... os níveis entre 10 e $30 \mathrm{mg} / \mathrm{dl}$ são de dificil interpretação. Daí pergunto aos senhores:

a) Se usarmos este limite $(30 \mathrm{mg})$ segundo as afirmações acima, estaríamos ou não, ocultando os riscos das interveniências dos stress patológicos tão freqüentes para estas crianças?

b) E o risco de se estabelecer limites minimos para requerimentos e reservas nutricionais, como se a condição humana devesse ter estágios para aguardar uma intervenção que pode chegar muito tarde? Esta falta de padronização de um ponto de corte, mais próximo de $50 \mathrm{mg}$ me parece de pouca efetividade como sinal de alarme para justificativa de uma ação em saúde pública.

4 - Outra questão que se coloca é sobre uma evidencia que encontrei nas discussões desses estudos de que a hipovitaminose $\mathrm{A}$, não está associada à D.E.P. pelo fato de algumas evidências terem apontado a pouca relação entre a avaliação antropométrica da D.E.P. e a avaliação bioquímica da Vit. A, como se pudéssemos extrapolar para o geral algumas particularidades de correlação antropométrica $x$ bioquímica, (ta. 
belas 9 e 10). No nosso entendimento, isto é perigoso porque :

a) Carece de uma confrontação bioquímica para a avaliação de proteínas totais e Vit. "A".

b) Isola e fragmenta o problema, abrindo portas para programas verticais específicos, fugindo assim à lógica dominante atual, na área de saúde coletiva de integrar as ações de saúde.

5 - A exposição dos dados apesar de contundentes de per se, sem a explicação dos reais determinantes sociais da doença, anacroniza a exposição e fragmenta a análise da questão na medida em que omite as condições materiais de vida de $80 \%$ da nossa população. Isto em ciência é abstração porque não relaciona os indivíduos e as classes sociais com os meios de produção. Refiro-me à constante explicação para determinação do problema nesses estudos de que a desnutrição e as demais doenças sociais são "Produto da ignorância nutricional das mães", conforme se lê em muitos relatórios, uma afirmação para nós, de fím de século!

Seria este posicionamento o que trata o relatório de Flores quando se refere "a visão clínica e visão básica"? Que significa isto?

$\mathrm{O}$ positivismo $\mathrm{x}$ estruturalismo.

Concluindo, reforço as proposições de se padronizar:

1) O método.

2) A revisão do ponto de corte para cima de $30 \mathrm{mg}$ e do índice crítico de prevalência. to de programas.

3) O período de estudos populacionais para efei-

4) Amostras mínimas para diagnóstico de significância estatística para implantação e avaliação de programas.

5) Que, onde e quando sejam necessárias as intervençōes com o suplemento nutricional, se faça através das ações integradas em saúde, desde que se esclareçam devidamente a familia-alvo e a população sobre os reais determinantes do problema nutricional e da necessidade dessa intervenção.

6) Que o INAN assuma de imediato, a ação do enriquecimento alimentar do leite, com Vit. A distribuida nos programas de suplementação do Governo. 